\title{
A qualitative descriptive study of SimWars as a meaningful instructional tool
}

\author{
Chaoyan Dong', Timothy C. Clapper ${ }^{2}$, Demian Szyld ${ }^{3}$ \\ ${ }^{1}$ Department of Emergency Medicine, New York University School of Medicine, USA \\ ${ }^{2}$ TC Curriculum and Instructional Design, LLC, USA \\ ${ }^{3}$ New York University School of Medicine, New York Simulation Center for the Health Sciences, USA
}

Correspondence: Chaoyan Dong, Department of Emergency Medicine, New York University School of Medicine, USA. Email: chaoyan.dong@nyumc.org

\begin{abstract}
Objectives: To investigate faculty and residents' perceptions of whether SimWars can serve as a meaningful instructional format for Emergency Medicine residents and to identify strategies to implement SimWars effectively in a residency training program.
\end{abstract}

Methods: In this descriptive interview study, 5 facilitators, 2 contestants, and 8 observers were recruited from an Emergency Medicine residency program at a large, urban, university-based, level-I trauma center. Interview questions were created with the guidance of the social constructivism theory. Participants were interviewed individually. Themes were identified associated with responses to these questions. Results: (1) SimWars can be a meaningful instructional tool; (2) Debriefings and a well-structured rubric are essential; (3) Competition motivates participants to do their best, but can have a negative impact on them; (4) Residents expect to use the clinical skills, patient management and teamwork skills practiced in SimWars; and (5) Residents need more training on teamwork, including Team Strategies and Tools to Enhance Performance and Patient Safety ${ }^{\mathrm{m}}$ (TeamSTEPPS).

Conclusions: With its focus on competition, SimWars can be effective in residents' training when debriefings are guided by well-structured rubrics.

Keywords: Competition, psychological safety, SimWars, simulation

\section{Introduction}

In January 2008, three emergency medicine physicians in the United States, Yasuharu Okuda, Scott Weingart, and Steven A. Godwin, had a vision for assessing teamwork, communication, and patient care using a fun, interactive, and meaningful medium (personal communication, 2011). As a result, SimWars, an onstage competition came into being. For participants and audience alike, SimWars shares similarities with popular television shows produced worldwide where musical contestants perform on stage and are judged by a panel of experts. Following the critique and debriefing, either the panel or an audience vote determines which contestants move on to the next round of competition. One such example in the United States is American Idol. In SimWars, clinical teams demonstrate their communication, teamwork, clinical management, and problem solving skills. Upon completion of each simulated clinical encounter, judges assess and discuss participants' clinical actions and team dynamics. Most often, the debriefing occurs on stage and in public and the audiences vote on a winner via an audience response system. Since its inception, SimWars have been staged at national meetings such as the annual International Meeting on Simulation in Healthcare (IMSH), the Society for Academic Emergency Medicine (SAEM), the American College of Emergency Physicians (ACEP) as well as locally in the form of citywide competitions.

The objectives of the study are to investigate whether a SimWars event held locally at a large, urban Emergency Medicine residency program is an effective educational program and how to best use features of SimWars, beyond entertainment, for educational purposes. No published research demonstrates the impact of SimWars on residents' learning. Therefore there are more questions than answers regarding SimWars for educational purposes. It is not clear how curriculum leaders should use SimWars to train residents or what curriculum design strategies should be used to enhance the residents' experience. How does SimWars' competitive nature affect residents' performance 
and learning outcomes? In simulation education, creating and preserving a psychologically safe learning environment is critical and can be challenging. ${ }^{1}$ This can be amplified in SimWars local events as inexperienced facilitators may create harsh conditions for participants, which could have detrimental impacts on current and future learning. Debriefing time constraints can limit opportunities to provide sufficient feedback for participants, especially at an individual level. For example, in a SimWars debriefing there is no opportunity to demonstrate the correct way of performing a procedure; as a result, incorrect skills and procedures can go uncorrected or superficially discussed. This qualitative research study is intended to elicit and analyze feedback from both facilitators and participants to help to assess the value of SimWars as well as areas for improvement. Specifically, the research questions include:

1. What are residents', facilitators', and observers' perception of the key elements of a SimWars session, including: teamwork, competition, debriefing, reflection on their own action, and social construction of knowledge?

2. What are strategies used to conduct a SimWars session?

\section{Theoretical framework}

The theory of social constructivism, research on competition, and psychological safety guided the design of our interview questions (see Table 1 for key elements of interview questions). The theory of social constructivism emphasizes that individuals create their own knowledge based on how they relate new information to what they have previously experienced, ${ }^{2}$ and additionally recognizes the value of social interactions in the learning process, meaning that people clarify personal conceptions as they interact with the understandings of others. ${ }^{2}$ When we encounter something new, we reconcile it with our previous ideas and experience, changing what we believe, or discarding the new information as irrelevant. In a SimWars session, residents collaborate and interact with one another while providing care for simulated patients. The goal is for participants to demonstrate and gain clinical knowledge, teamwork and communication, and patient management skills. The constructive process involves not only residents' prior knowledge and experience in the clinical scenarios, ${ }^{3,4}$ but also the psychosocial factors such as motivation, anxiety, and stress, which have been shown to impacts learners' performance., ${ }^{5,6}$ The learning outcome is optimal when learners are free from threat, least defensive, and want to learn. ${ }^{1,3}$ The SimWars experience theoretically combines collaboration with peers and competition which requires both psychological safety and simultaneously induces stress. With regards to collaboration in healthcare settings, the Agency for Healthcare Research and Quality (AHRQ) and the Joint Commission (TJC) have identified four competencies for teamwork for clinical education: leadership, communication, situational monitoring, and mutual support. ${ }^{7}$
These competencies are based on research on the crew resource management and human factors principles that improve patient safety and clinical performance. ${ }^{8}$ Effective clinical teamwork and collaboration also requires psychological safety and a culture of learning. ${ }^{1}$ These key features were the foundation for our interview questions.

Table 1. Key elements of the interview questions

\begin{tabular}{ll}
\hline Key elements & \\
\hline Debriefing & $\begin{array}{l}\text { Prior debriefing experience } \\
\text { Strategies for debriefing }\end{array}$ \\
Psychological factors & $\begin{array}{l}\text { Competition } \\
\text { Pressure } \\
\text { Stress } \\
\text { Anxiety } \\
\text { Psychological safety } \\
\text { Prior knowledge in this scenario } \\
\text { Prior experience in SimWars } \\
\text { Motivation factors } \\
\text { Effectiveness of SimWars } \\
\text { Features those are helpful for learning } \\
\text { Simulation fidelity } \\
\text { Knowledge transfer } \\
\text { Leadership } \\
\text { Situational awareness } \\
\text { Communication } \\
\text { Mutual support } \\
\text { Reflection on action: Reflecting on the actions of } \\
\text { the learner and the frames of references they may } \\
\text { have for performing that action. } \\
\text { Social construction of knowledge: Team members } \\
\text { assist one another through action and word with } \\
\text { gathering, interpreting, analyzing, and classifying } \\
\text { new information to build upon or restructure } \\
\text { existing frames of reference. }\end{array}$ \\
\hline
\end{tabular}

Note: Teamwork competencies came from TeamSTEPPS $₫$ (Team Strategies and Tools to Enhance Performance and Patient Safety) by the Department of Defense, in collaboration with the Agency for
Healthcare Research and Quality (AHRQ), as an evidence-based teamwork system aimed at optimizing
patient outcomes by improving communication and teamwork skills among health care professionals patient ou
(2006).

\section{Methods}

A descriptive interview design was selected due to the exploratory nature of the research questions. A descriptive research design is a widely used qualitative research method used to gather information about a particular situation. ${ }^{9}$ Interview is one of the three main types of data collection methods in descriptive research design. ${ }^{10}$ The focus of this study was on the experience of individual participants, observers and facilitators in an Emergency Medicine Residency SimWars competition. Predetermined interview questions were used, and participants were encouraged to expand upon their answers in an investigative manner, which often lead to more detailed, in-depth information.

\section{Participants and data collection}

This study was approved by the Institutional Review Board (IRB) at the New York University (NYU) School of Medicine, a large, urban, university with a level-I trauma center. Participants were residents and faculty members at the Department of Emergency Medicine in the NYU School of Medicine. They were briefed on the purpose of the study and the potential risks and benefits. They were informed that their decision to participate in the study would have no impact on their academic or professional standing at the institution and that their responses would be de-identified. 
Informed consent was obtained and interviews were conducted in private with each lasting 30 to 45 minutes.

Fifteen interviews, including 5 facilitators, 2 participants, and 8 observers were completed following a SimWars session in the Emergency Medicine residency training program at NYU School of Medicine. The facilitators included faculty members and senior residents. The participants included those competing in and observing the SimWars competition.

\section{Interview questions}

The interview questions are listed in Appendix 1. The interview questions were tailored to the person's role in the SimWars competition. For example, questions for facilitators focused on case scenario design, debriefing, and serving as judges. Questions for faculty panelists focused on how the team cared for the patients and their clinical accuracy. Questions for SimWars participants focused on teamwork, attitudes during SimWars, levels of motivation, and responses to the facilitators' feedback. Questions for the observers had the same focus as that for the participants, except that they were told to answer from an observer's perspective.

\section{Data analysis}

Qualitative data analysis methods were used to identify themes associated with the responses to these questions. The data were coded using Atlas.ti ${ }^{11}$ software, a secure, PCbased software tool, which enabled researchers to discern the themes in the audio data (from interviews) to explore the relationships among the themes. Two researchers independently reviewed the interview data and made note of specific comments to discern themes and develop a coding scheme (CD and TC), followed by the complete research team analyzing the findings. Dominant themes were identified by iteratively comparing the data to ascertain recurrent themes using a bottom up coding strategy and quantifying their significance. ${ }^{12}$ Comments were categorized into a branching tree of thematic labels. Analysis was done until we obtained a state when additional layering of themes and stakeholder analysis yielded no new information from additional data. ${ }^{13}$ Although the sample size is adequate to answer the research questions ( 5 facilitators, 2 participants, and 8 observers), we are unable to categorize the results based on specific roles.

\section{Results}

The interview questions focused on the key elements such as teamwork, debriefing, psychological factors, issues related to SimWars, and future improvements. The results regarding each key element were presented as following.

\section{Teamwork}

Teamwork is the most frequently discussed theme among all the interviewees. Teamwork was addressed in the following four aspects: leadership, mutual support, communica- tion, and situational awareness. Table 2 summarized key codes and associated quotations.

- Leadership. All participants agreed that there was a clear leader during the SimWars session, and the leader received support from other members.

- Mutual Support. Mutual support means that the team members support one another during the SimWars. Among the 11 who addressed this issue, 9 said mutual support was obvious among team members, which entailed clear roles and responsibilities of team members and support of one another.

- Communication. Among the 14 who addressed communication issues, 8 said communication was great among the teammates; while 6 said they could do better. However, when asked to provide specific examples, including closed-loop communication and check-backs, few were able to do so.

- Situational Awareness. Situational awareness involves each team member scanning the situation to understand the environment and the patient status. Often, it is a prelude to mutual support to the leader or another team member. Situational awareness empowers each team member to speak up and call out solicited and unsolicited information that can influence patient care outcome. This competency raised the most controversies. Five had different interpretations of situational awareness, such as the participants' understanding of the environment. Among the seven who interpreted situational awareness as the understanding of the team dynamics, 5 said the team did a great job and 2 thought they did an average job.

Table 2. Teamwork related key codes and quotations

\begin{tabular}{ll}
\hline Key Codes & Quotations \\
\hline Leadership & $\begin{array}{l}\text { "I think that, uh, there was a clear leader, um, that } \\
\text { identified themselves and took charge, and, uh, } \\
\text { was...um... really delegating responsibilities. So, I don't } \\
\text { know, pretty good leadership in those regards." } \\
\text { "I think the leader was supporting the group but there } \\
\text { Mutual support } \\
\text { could be more communication from the other team } \\
\text { members." }\end{array}$ \\
$\begin{array}{l}\text { "I think mostly the team members need to be more } \\
\text { assertive in getting their point across but also the } \\
\text { leader needs to be more receptive to that." } \\
\text { "I didn't hear enough bottom-up communication. } \\
\text { "Yeah I think they- they hadn't really grasped the } \\
\text { capacity for them to- to really know the things were } \\
\text { being done because it's so artificial." } \\
\text { "So when someone says they don't really see them } \\
\text { putting the urine catheter in or they don't see them } \\
\text { putting the intravenous line in, so they don't really know } \\
\text { what's happening and they're not watching what they're } \\
\text { doing then. Normally they would be watching when you } \\
\text { put the central venous [sp] line in- into the chest." }\end{array}$
\end{tabular}

\section{Debriefing}

The participants commented on debriefing strategies and the key elements in the debriefing sessions.

- The debriefing sessions should include positive feedback and also offer suggestions for future improvement. ${ }^{14}$ 
- The debriefing session should be structured to include comments on clinical skills as well as patient management and organizational skills.

- A rubric based on the learning objectives should be used to guide the debriefing.

- Debriefing should include input from audience members, rigid grading scales, and take-home sheets to highlight the key points.

Table 3. Key codes and quotations related to psychological factors

\begin{tabular}{|c|c|}
\hline Key codes & Quotations \\
\hline $\begin{array}{l}\text { Stress and the impact of } \\
\text { stress on performance }\end{array}$ & $\begin{array}{l}\text { “... you're taking a bunch of type A people you } \\
\text { know, they're going to be compared to the other } \\
\text { group- definitely, um, will, I think it may- you } \\
\text { know it depends on the person but in some } \\
\text { cases it may improve their performance, in } \\
\text { some cases it may hurt their performance.” }\end{array}$ \\
\hline $\begin{array}{l}\text { Impact of being } \\
\text { observed }\end{array}$ & $\begin{array}{l}\text { "I think the competition is somewhat helpful. I } \\
\text { think the thing that's difficult with SimWars is } \\
\text { you're doing it in front of your peers and, you } \\
\text { know, feeling like if you make a silly mistake } \\
\text { you'll be looked down upon." } \\
\text { "It probably makes me a little more anxious, but } \\
\text { at the same time I don't think it really changes } \\
\text { what we do, just that sometimes there are } \\
\text { twenty, thirty people in the trauma slot watching } \\
\text { you and it's just the nature of medicine." }\end{array}$ \\
\hline $\begin{array}{l}\text { Impact of competition } \\
\text { on the audience }\end{array}$ & $\begin{array}{l}\text { "They'll remember certain things, reinforce } \\
\text { learning, and the competition will maybe make } \\
\text { the audience more focused. For the participant, } \\
\text { l'm not clear, but I guess, I would expect that } \\
\text { perhaps the participant would try to do a little } \\
\text { better than the other team. But um- it's unclear } \\
\text { to me whether it would be better without } \\
\text { competition. For the audience, it's probably a } \\
\text { little better because it's more repetitive and } \\
\text { people try, people try to maintain attention and } \\
\text { make it more entertaining." }\end{array}$ \\
\hline $\begin{array}{l}\text { Competition as } \\
\text { entertainment }\end{array}$ & $\begin{array}{l}\text { "You know a lot of us are competitive and, um, } \\
\text { mostly friendly competition you know? And I } \\
\text { thought it was a friendly competition and that } \\
\text { just sort of added to the fun of it, and the } \\
\text { motivation." }\end{array}$ \\
\hline $\begin{array}{l}\text { Preservation of } \\
\text { psychological safety }\end{array}$ & $\begin{array}{l}\text { "Me personally? Very safe. I mean, again, I think } \\
\text { it comes down to different people's personali- } \\
\text { ties. I think some people are better suited for } \\
\text { sort of working in front of a crowd than others. } \\
\text { I think that...definitely was not preserved, but } \\
\text { that's the nature of performing simulations in } \\
\text { front of a large group, it's just, there's, I mean I } \\
\text { can tell you that, um, I've seen those people } \\
\text { perform better in a real clinical environment than } \\
\text { they did in front of the group." }\end{array}$ \\
\hline
\end{tabular}

\section{Psychological factors}

Table 3 presented the key codes on psychological factors and associated quotations. Eight participants indicated that psychological safety was preserved during SimWars, while two said it was not. Psychological safety was best preserved when the debriefers focused on group, rather than individual performance. Regarding the impact of stress on participants' performance, 5 out of 6 who answered the question said that the participants were more anxious in the competitive environment but could do better in a real clinical environment. One participant indicated that the residents were well-trained, and the pressure did not affect their performance.

\section{Issues related to SimWars}

Table 4 summarizes the key codes and associated quotations related to SimWars. All the interviewees agreed that SimWars was helpful for the following reasons:

- learning by doing without putting patients in risk

- putting what you read in books to use

- practicing teamwork skills

- preparing for boards

- learning rare clinical situations, and reviewing those already known

The most helpful parts of SimWars include:

- simulation experience that includes debriefing and instruction on medical knowledge

- caring for virtual patients in realistic simulation scenarios

- different years of residents learning together

Table 4. Key codes and quotations related to SimWars

\begin{tabular}{|c|c|}
\hline Key Codes & Quotations \\
\hline \multirow[t]{2}{*}{ How is SimWar useful? } & $\begin{array}{l}\text { "Because the best learning is from patient } \\
\text { cases, at least for me and most people in } \\
\text { emergency medicine. I think were kind of like } \\
\text { learners by doers, and this way you get to do } \\
\text { something, sort of learn on a patient but it's not } \\
\text { actually going to impact the patient, real } \\
\text { patients care." }\end{array}$ \\
\hline & $\begin{array}{l}\text { "And that's good for the boards as well. I think } \\
\text { because those, it's even more of an artificial } \\
\text { situation than SimWars. And I like having } \\
\text { fun...um...and it's entertaining, and it gets you } \\
\text { involved in trying to see who is the best." }\end{array}$ \\
\hline \multirow[t]{3}{*}{$\begin{array}{l}\text { The most helpful } \\
\text { part of SimWars }\end{array}$} & $\begin{array}{l}\text { "What was really helpful was having the } \\
\text { lecture on the topic happen after." }\end{array}$ \\
\hline & $\begin{array}{l}\text { "It makes you think in real time and readjust } \\
\text { your decision based on vital signs and based } \\
\text { on clinical status of the patient." }\end{array}$ \\
\hline & $\begin{array}{l}\text { "I think it works well together because, you- } \\
\text { even if the person who is participating in the } \\
\text { SimWars, or in the simulation session, is not } \\
\text { doing } 100 \% \text { of the right actions, then you can } \\
\text { still have, you need to have that debriefing } \\
\text { session in order to understand what you } \\
\text { should take away from the learning session." }\end{array}$ \\
\hline $\begin{array}{l}\text { Opinions of simulation } \\
\text { fidelity }\end{array}$ & $\begin{array}{l}\text { "They got caught up in the idea and they didn't } \\
\text { get caught up in being a doctor and looking at } \\
\text { the whole thing so that... it can be so artificial } \\
\text { that you play the game of taking care of the } \\
\text { problem and you don't really show how you do } \\
\text { it." } \\
\text { "I mean it is more real than any other learning } \\
\text { tool that I have seen. It's not perfect. It's not a } \\
\text { living breathing human, but certainly the stress } \\
\text { of a real person is simulated by the fact that } \\
\text { there are } 50 \text { people watching you, and you } \\
\text { know, it is very close. Is it perfect? It's not } \\
\text { perfect, but it's very close." }\end{array}$ \\
\hline \multirow[t]{2}{*}{ Knowledge transfer } & $\begin{array}{l}\text { "They're going to be more cognizant of starting } \\
\text { CPP, monitoring and the people who partici- } \\
\text { pated are going to be more cognizant." }\end{array}$ \\
\hline & $\begin{array}{l}\text { "I think it's somewhat helpful but I think more } \\
\text { importantly, the operational skills and the } \\
\text { leadership roles are the things that you can } \\
\text { practice more here and you don't feel, people } \\
\text { don't usually get a chance to experiment on } \\
\text { how they would do those things." }\end{array}$ \\
\hline
\end{tabular}


Participants also commented on simulation fidelity or the physical realism associated with the simulator or the simulation environment. All the interviewees said that the simulation is an artificial environment that resembles but does not replicate a real clinical scenario. Three interviewees noted that although the scenarios were not realistic, simulation and SimWars seemed to be an effective teaching tool. They offered suggestions for making the scenario and participants' actions more realistic, for example using make-up and other moulages to make the simulated patient look ill and more human, or situating participants in "ifthen" scenarios where participants' actions are clinically consequential through making the simulation conceptually and emotionally relevant. ${ }^{15}$

Regarding the question of whether residents can transfer what they learn from SimWars into patient care, all participants perceived that these skills would be transferred to the clinical setting. Depending on the case scenario, residents are faced with a situation that rehearses rare clinical events, requires complicated clinical skills, reviews a familiar case, and/or exercises patient management and leadership skills.

\section{Future improvement}

Future improvement focuses on realism of simulation, participants' involvement, debriefing, and the structure of the SimWars. Table 5 includes details for these aspects.

Table 5. Future improvement to use SimWars in residents training

\begin{tabular}{ll} 
Key codes & Quotations \\
\hline Realism & $\begin{array}{l}\text { "Create an environment that people believe and that } \\
\text { they're so immersed in it, you know as close as possible } \\
\text { to a real patient." } \\
\text { "To run the simulation sessions with your actual team that } \\
\text { you are working with in real life just to make it more } \\
\text { realistic." }\end{array}$ \\
"Get participants involved." \\
Debriefing & $\begin{array}{l}\text { "Handouts include the key learning points." } \\
\text { "Structured scoring sheets" } \\
\text { "Participants should be informed of what will be evaluated } \\
\text { before the case." } \\
\text { "There probably should be a separate time where the } \\
\text { judges... go over things in a much more detailed fashion, } \\
\text { but not in front of the group." } \\
\text { "The session should be videoed and then were able } \\
\text { to...play it back for the individual groups and have them } \\
\text { watch themselves, and they would probably be the most } \\
\text { critical of their own." } \\
\text { "More difficult cases" } \\
\text { "Without observers" } \\
\text { "Competitions between teams are not necessary in the } \\
\text { sense of facilitating learning." }\end{array}$ \\
Structure &
\end{tabular}

\section{Discussion}

\section{SimWar as an instructional format}

This study indicates that SimWars can serve as a meaningful instructional format to train residents' clinical knowledge, communication, and teamwork skills when used as part of a comprehensive education program. In this study, SimWars was used as an alternative to the weekly simulation sessions in the Emergency Medicine residency program. However, there was still a need to review the clinical topics as well as communication and teamwork skills as indicated in the learning objectives of the SimWars session.

Previous research indicates that educational goals should match the format of simulation technology for teaching. ${ }^{16}$ In this study, the simulated patient has lifelike full-body features that display symptoms such as heart rate and blood pressure, and responds to physical interventions such as chest compressions. The decision to use a hi-fidelity simulator was based on the objectives of the SimWars scenario to allow the residents to accomplish specific clinical interventions. However all interviewees commented that the simulated patient is not a real patient, which made it difficult to treat him or her as a real patient. For example, intubation, a frequently mistaken procedure that requires extensive practice, was not performed by any of the teams, although it was a key step in the particular trauma scenarios. To improve realism of SimWars, one suggestion is to use make-up and other moulages to make simulated patients look ill and believable. When the realism of the simulator or the environment is augmented, we refer to this as increasing the fidelity. ${ }^{17}$ In the absence of realistic features, leaders of SimWars could appeal to an informal contract as suspension of disbelief, including specifying the limitations of the simulator and the expectation of the participants to treat the simulated clinical situation as a real event. This could help manage learners' expectations and may encourage higher quality performances.

\section{Teamwork training}

Teamwork training has been recognized as an important educational goal by federal quality and regulatory agencies as well as academic societies, medical boards, and residency review committees. In our study, participants were able to apply some of the four TeamSTEPPS competencies, including leadership, mutual support, communication, and situational awareness. However, additional training is indicated. In addition, some residents participated in roles outside of their profession, including portraying the role of nurses. It will be interesting to see how residents perform as part of an interprofessional team in SimWars competitions.

\section{Debriefing}

Our results demonstrated the critical role of debriefing in SimWars, in accordance with previous research studies. ${ }^{18}$ The results also point out the key elements of effective debriefing, which is consistent with the best practice discussed in prior studies ${ }^{19,20}$ Debriefing should include formative feedback with the goal of improving participants' performance. A well-constructed debriefing rubric could assist with this task, in particular at the level of identifying the performance gap. ${ }^{21}$

\section{Psychological factors}

Psychological factors such as stress, anxiety, and fatigue have been shown to play critical roles in patient care..$^{5,6,22-24}$ In simulated patient care, these factors have similar impact 
on performance. The distinctive feature of SimWars is competition. Our participants' responses toward competition are mixed, largely depending on individual's ability to handle competition. Overall, competition added novelty to simulation curriculum. Competition can have a doubleedged impact on the participants. Competition, on one hand, motivates participants to do their best; while on the other hand can have a negative impact on participants. Because SimWars require patient assessment and care in front of audience, participants experience more stress than in some other simulation activities. Interviewees agreed that the debriefers tried hard to reduce the pressures posed to the participants by reassuring them and providing positive feedback.

Stress has similar impact on performance as competition. The impact can be best described by the YerkesDodson curve that performance increases with physiological or mental arousal, but only up to a point; when levels of arousal become too high, performance decreases. ${ }^{25}$ In SimWars, stress could be induced from peers' observation and/ or evaluation by attending physicians. All interviewees agreed that the participants in SimWars experienced observational pressure and individuals may use different strategies to address these feelings. It is possible that competition and stress might contribute to knowledge transfer since practicing under pressure seems to improve performance under similar circumstances. ${ }^{26}$

\section{Knowledge transfer}

No matter what format of simulation technology is used, the ultimate goal is to improve patient care outcomes, which is the highest level of the Kirkpatrick hierarchy, a widely used classification for training outcomes. ${ }^{27}$ Like any other formats of medical simulation, SimWars may not occur in an actual patient care environment and some learners may not make the connections or transfer what has been learned in the simulation environment to clinical practice. Whether the knowledge gain through SimWars can be transferred to patient care has to be addressed through longitudinal follow-up research. Studies of this type are very difficult to design and to execute. ${ }^{28}$ However, without reservation all interviewees perceived that residents will use these skills in their future practice, including clinical skills, patient management, and teamwork skills. Further studies are required to investigate residents' immediate knowledge gain and skill acquisition as well as skill transfer to clinical settings.

\section{Implications, limitations and future work}

This study showed that faculty and resident perceived SimWars as an effective instructional tool when combined with lectures. To maximize SimWars' instructional value, faculty should consider teaching teamwork and communication using TeamSTEPPS as a guide. The use of rubrics to guide the objectives and the debriefing process also adds value to the SimWars competition. SimWars in our study consisted of clinical content in a single topic area - gastro- intestinal bleeding. A few of the interview questions are scenario-dependent. It is possible that a different clinical topic area might yield different answers for the same questions. This problem can be solved by interviewing a different group of residents who will go through the same clinical scenario, and by interviewing the same group of residents after they go through a different case scenario. It will be interesting to compare the data to see whether different scenarios yield different outcomes. This was a local competition. The effects of a national setting or performing outside the home institution may increase stress or otherwise affect the experience for both organizers and learners. The larger sample size and the more extensive data will enrich our understanding of SimWars as an instructional format in medical simulation.

\section{Acknowledgements}

We thank all the participants in the study who invested their time and energy to take part in the study and provided invaluable input for the article. We also thank Matthew Williams for assisting us in conducting interviews, transcribing the interviews results and data analysis. We also thank Jaclyn Munson for assisting us in IRB application, conducting interviews, and transcribing the interview data. This study was not supported by any research funding.

\section{Conflict of Interest}

The authors declare that they have no conflict of interest.

\section{References}

1. Nembhard IM, Edmondson AMYC. Making it safe: the effects of leader inclusiveness and professional status on psychological safety and improvement efforts in health care teams. Health Care. 2006;966:941-966.

2. Piaget J. Intellectual evolution from adolescence to adulthood. Human Development. 2008;51:40-47.

3. Clapper TC. Beyond Knowles: what those conducting simulation need to know about adult learning theory? Clinical Simulation in Nursing. 2010;6:e7-e14.

4. Clapper TC. Development of a hybrid simulation course to reduce central line infections. Journal of Continuing Education in Nursing. 2012;43:218224.

5. Crane M. Why burned-out doctors get sued more often. Medical Economics. 1998;75:210-218.

6. Shanafelt TD, Sloan JA, Habermann TM. The well-being of physicians. The American Journal of Medicine. 2003;114:513-519.

7. TeamSTEPPS Home. 2013 [cited 6 Feb 2013]; Available from: http://teamstepps.ahrq.gov.

8. Clapper TC, Kong M. TeamSTEPPS ${ }^{\oplus}$ : the patient safety tool that needs to be implemented. Clinical Simulation in Nursing. 2012 [cited 4 Feb 2012];8:e367-e373.

9. Mertens DM. Research and evaluation in education and psychology: integrating diversity with quantitative, qualitative, and mixed methods. Thousand Oaks, CA: SAGE Publications Inc.; 2005.

10. Jackson SL. Research methods and statistics: a critical thinking approach. $3^{\text {rd }}$ ed. Belmont, CA: Wadsworth; 2009.

11. Dowling M. Atlas.ti (software). In: Given L, editor. The SAGE encyclopedia of qualitative research methods. Thousand Oaks, CA: SAGE Publications Inc.; 2008.

12. Creswell JW. Qualitative inquiry and research design: choosing among five traditions. Sage Publications; 1998.

13. Goldman-Segall R. Configurational validity: a proposal for analyzing multimedia ethnographic narratives. Journal for Educational Multimedia and Hypermedia. 1995;4:163-182. 
14. MacLean PD. The triune brain in evolution: role in paleocerebral functions. Plenum Press; 1990.

15. Rudolph JW, Simon R, Raemer DB. Which reality matters? Questions on the path to high engagement in healthcare simulation. Simulation in Healthcare: Journal of the Society for Simulation in Healthcare. 2007;2:161163.

16. Scalese; RJ, Issenberg; SB. Simulation-based assessment. In: Holmboe E, Hawkins R, editors. Practical guide to the evaluation of clinical competence. Philadelphia, PA: Elsevier; 2008

17. AGARD. Fidelity for pilot training. Advisory group for aerospace research and development. London: 1980.

18. Domuracki KJ, Moule CJ, Owen H, Kostandoff G, Plummer JL. Learning on a simulator does transfer to clinical practice. Resuscitation. 2009;80:346-349.

19. Salas E, DiazGranados D, Weaver SJ, King H. Does team training work? Principles for health care. Academic Emergency Medicine Official Journal of the Society for Academic Emergency Medicine.2008;15:1002-1009.

20. Fanning RM, Gaba DM. The role of debriefing in simulation-based learning. Simulation in Healthcare Journal of the Society for Simulation in Healthcare. 2007;2:115-125.

21. Rudolph JW, Simon R, Raemer DB, Eppich WJ. Debriefing as formative assessment: closing performance gaps in medical education. Academic
Emergency Medicine Official Journal of the Society for Academic Emergency Medicine. 2008;15:1010-1016.

22. Croskerry P. Achieving quality in clinical decision making: cognitive strategies and detection of bias. Academic Emergency Medicine Official Journal of the Society for Academic Emergency Medicine. 2002;9:11841204.

23. Haas JS, Cook EF, Puopolo AL, Burstin HR, Cleary PD, Brennan TA. Is the professional satisfaction of general internists associated with patient satisfaction? Journal of General Internal Medicine. 2000;15:122-128.

24. Shanafelt TD, West C, Zhao X, Novotny P, Kolars J, Habermann T, et al. Relationship between increased personal well-being and enhanced empathy among internal medicine residents. Journal of General Internal Medicine. 2005;20:559-564.

25. Yerkes RM, Dodson JD. The relation of strength of stimulus to rapidity of habit-formation. Journal of Comparative Neurology and Psychology. 1908;18:459-482.

26. Beilock S. Choke: what the secrets of the brain reveal about getting it right when you have to. Free Press; 2011

27. Kirkpatrick DL. Evaluating training programs: the four levels. BerrettKoehler; 1998.

28. McGaghie WC, Issenberg SB, Petrusa ER, Scalese RJ. A critical review of simulation-based medical education research: 2003-2009. Medical Education. 2010;44:50-63.

\section{Appendix 1. Interview Questions}

\section{Facilitators}

1. What was your role in the SimWars session?

2. Debriefing

What strategies did you use in the debriefing session? (e.g., motivating factors)

How much do you know about the participants' prior knowledge in the

a. Clinical topics addressed in the SimWars session

b. Teamwork topics addressed in the SimWars session?

What was the participants' prior experience in SimWars?

How well do you think that the debriefing session accurately assess the residents' skills?

3. Teamwork

How well do you think that the teams perform based on the following factors?

a. Leadership

b. Situational awareness

c. Communication

d. Mutual support

4. Reflection on action (scenario-dependent)

For example: I noticed that you began chest compressions after securing the pads from the defibrillator. How did that relate to the way you learned that task?

5. Psychosocial factors

Was psychological safety preserved during debrifing/SimWars?

Do you think whether the questions asked are psychologically threatening to residents?

6. Transfer of knowledge

How much do you think that residents can transfer what they learned from this session to their clinical practice?

7. Competition

What is the impact of competition on their performance?

8. Improvement What should be done differently to improve the SimWars session?
Residents (participants \& observers of the SimWars session)

1. Do you think that the SimWars session a useful learning experience for you?

2. How real was the learning experience in comparison to real patient scenarios?

3. Which part of the session do you think most helpful for you? Why?

4. Teamwork

During the SimWars session, what do you think about your team in the following four competencies of teamwork?

a. Leadership

b. Situational awareness

c. Communication

d. Mutual support

5. (Scenario-dependent)

a. Your prior knowledge in the content in this scenario

b. Prior experience in SimWars

6. Debriefing

How does the debriefing session help you learn?

How could the debriefing experience be improved?

7. Psychological safety

How safe do you feel in making errors in the SimWars session?

8. Transfer of knowledge

How much do you think that you can use what you have learned from this session to your clinical practice?

How might you have learned more than you think you have?

9. How would you assess your own clinical skills change specifically for this scenario (before and after the SimWars session)?

10. Competition

What is the impact of competition on their performance?

11. Improvement

What should be done differently to improve the SimWars session? 